\title{
Current global standards for chemical protective clothing: how to choose the right protection for the right job?
}

\author{
Eric VAN WELY \\ ${ }^{1}$ DuPont Protection Solutions, Global Regulatory Affairs, DuPont Geneva, Switzerland \\ Received July 17, 2017 and accepted October 10, 2017 \\ Published online in J-STAGE October 17, 2017
}

\begin{abstract}
The first standards for chemical protective clothing (CPC) emerged mid to late 1980's and have evolved since as most standards are revisited every $5 \mathrm{yr}$. Over the past years, we have also seen a strengthening of the chemical and worker protection legislation around the globe (various forms of REACH) but also protection of workers. The most prevalent standards originate under the auspices of the International Standards Organisation (ISO), European Committee for Standardisation (CEN) or under various US standards organisations (e.g. NFPA, ASTM). Protective clothing against hazardous materials is required in many of the professional and non-professional activities of everyday life. Effective and adequate protection is important in many scenarios from household (e.g. cleaning agents, peroxides, acids and bases, paints), to agricultural (e.g. fuel, pesticides), to medical (e.g. pharmaceuticals and active ingredients), to industrial production (e.g. petro-chemicals, chemicals, paints, adhesive and coatings) but also manufacturing of many products (e.g. light bulbs, cars, semi-conductors), during various emergency activities (e.g. boat, rail or road accidents as well as fire-fighting in an urban and industrial setting), and finally, military operations or response to incidents of terrorism. Nevertheless, CPC must remain the last line of defence whenever possible through a preference for less hazardous chemicals, less dangerous processes and handling operations, and by engineering controls to reduce and minimise human contact with the chemicals. This article provides information about the selection, use, care and maintenance (SUCAM) of protective clothing against chemical and microbiological hazards.
\end{abstract}

Key words: ISO, International standards, chemical protective clothing, chemical protection, risk assessment, SUCAM (Selection, Use, Care, Maintenance), PPE

\section{Introduction}

No chemical protective clothing can protect against all levels of chemical risk due different exposure scenarios, the chemical properties, the different types of barriers (fabrics and coatings available) and other aspects such as mechanical resistance and the comfort of the wearer.

To whom correspondence should be addressed.

E-mail: eric.a.van-wely@dupont.com

Chair of ISO TC94 SC13 Sub-Committee on Protective Clothing

(C)2017 National Institute of Occupational Safety and Health
Selection of chemical protective clothing (CPC) needs to be made for specific chemical exposure scenarios which include the work situation (time duration, space constraints), the chemical(s), source of exposure, length of exposure time, barrier penetration and permeation properties, garment seam and closure types, and work environmental conditions (temperature and humidity).

Therefore, standards play a huge role in helping the user select the right garment for protection. Standards set minimum specifications of protective clothing, build a hierarchy through protection levels, a level of quality, compara- 


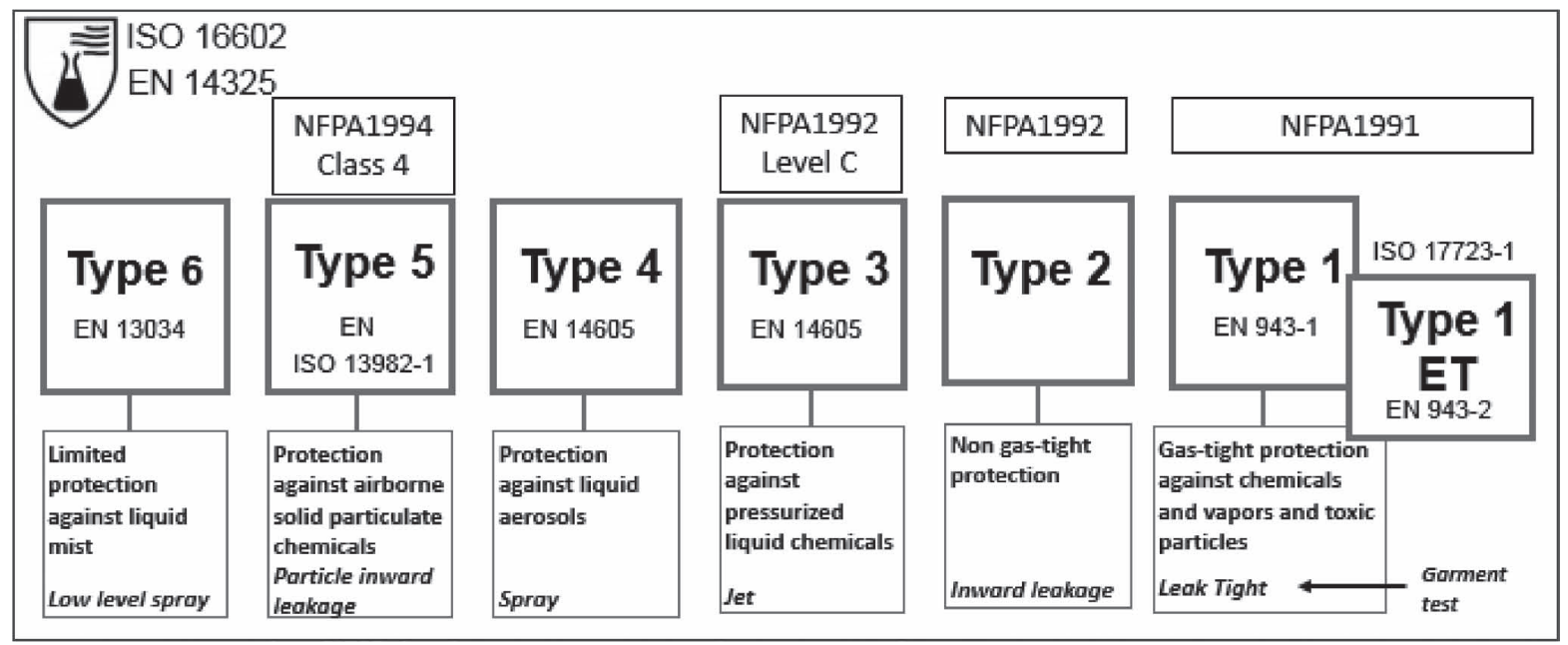

Fig. 1. General overview and comparison between the different standards globally.

bility of products, and the selection of the right PPE based on risk assessment. Standards take a long time to develop, agree and harmonise between countries or consensus standard organizations with lengthy consultation periods ${ }^{1-4)}$.

\section{Overview about CPC Standards and Legal Requirements}

\section{General}

There are three types of standards: test methods, product or performance specifications, and technical reports or guidance documents. Test methods describe how a specific test shall be performed and what shall be observed. These try to replicate possible real-life exposures using either on a lab bench scale or full garment tests. Test methods do not set a specification or limit; these are provided in product or performance specification standards. Performance specifications list the test methods to be used and assign pass fail criteria or set different levels of performance that must be met for different properties related to hazards or risks. This article focuses on the latter type of standards.

\section{ISO standards}

The most common ISO and CEN CPC standards refer to six basic types of protective clothing against chemicals plus additional standards related to infective agents. These Types are based on full garment tests, i.e. Low level spray test for Type 6, Particle inward leakage test for Type 5, Spray test for Type 4, Jet test for Type 3, Inward leakage test for Type 2 and some Type 1 (i.e. Type 1c and some Type 1b), Leak Tight test (Internal pressure test) for Type 1 and Type 1-ET; see listing at the bottom of the boxes below each Type and its corresponding EN standard in Fig. 1.

In the US, CPC is often broadly characterized into one of 4 "Levels" (A through D; see Table 2)) based on health risk to skin and respiratory system as outlined by USA OSHA and EPA. Only three of these levels (i.e. A, B and C and not $\mathrm{D}$ ) are comparable, to ISO/CEN types. In addition, there are many performance classes for the requirements and within each ISO/CEN type, the efficacy against different chemicals and microbes and the mechanical strength varies depending on the fabric structure and properties, the seam type and the construction of the whole clothing. Types 3, 4, and 6 also include partial body protection of the wearer (e.g. apron, sleeves, etc.).

Under ISO, there are two product standards ISO 16602 and ISO 17723-1 (still in draft) that cover: for the first standard, the industrial/professional and consumer applications, and the second the Emergency Teams ${ }^{5,6)}$. For the ISO 16602 description of the types, see the description of the CEN Types, i.e. the description at top of the box below each Type and its corresponding EN standard. As stated earlier, the origin of Types is based on the "full garment tests". Therefore, there is no direct hierarchy between different garment Types as the garment test differs for each Type, but an implicit one as the materials' chemical barrier and mechanical properties and robustness of seams and closures have to increase from Type 6 to Type 1 in order to pass the Type-specific garment test.

ISO 17723-1 is a specification for PPE ensembles, which provide protection against chemicals, including gases, vapours, liquids and particles during hazardous response by emergency response teams, with optional requirements for biological and chemical warfare (terror- 
Table 1. Test for Type 1 to type 6 CPC according to EN 14325 and ISO $16602^{10-19)}$

\begin{tabular}{|c|c|c|c|c|c|c|c|c|c|}
\hline & $\begin{array}{l}\text { Chemical } \\
\text { Permeation } \\
\text { ISO } 6529\end{array}$ & $\begin{array}{l}\text { Chemical } \\
\text { Penetration/ } \\
\text { repellency } \\
\text { ISO } 6530\end{array}$ & $\begin{array}{c}\text { Abrasion } \\
\text { ISO } \\
12947-2 \\
\text { (EN 530) }\end{array}$ & $\begin{array}{c}\text { Flex } \\
\text { cracking } \\
\text { ISO } 7854\end{array}$ & $\begin{array}{l}\text { Tear } \\
\text { ISO } \\
9073-4\end{array}$ & $\begin{array}{c}\text { Tensile } \\
\text { ISO } \\
13934-1\end{array}$ & $\begin{array}{c}\text { Puncture } \\
\text { ISO } \\
13996 \\
\text { (EN863) }\end{array}$ & $\begin{array}{c}\text { Seam } \\
\text { Strength } \\
\text { ISO } \\
13935-2\end{array}$ & Other \\
\hline Type 1 & $\mathrm{x}$ & & $\mathrm{x}$ & at normal/low temperature & $\mathrm{x}$ & $\mathrm{x}$ & $\mathrm{x}$ & $\mathrm{X}$ & ignition \\
\hline Type 2 & $\mathrm{x}$ & & $\mathrm{x}$ & at normal/low temperature & $\mathrm{x}$ & $\mathrm{x}$ & $\mathrm{x}$ & $\mathrm{X}$ & ignition \\
\hline Type 3 and 4 & $\mathrm{x}$ & & $\mathrm{x}$ & at normal/low temperature & $\mathrm{x}$ & $\mathrm{x}$ & $\mathrm{x}$ & $\mathrm{X}$ & \\
\hline Type 5 & $\begin{array}{l}\text { particula } \\
\text { penetration }\end{array}$ & $\begin{array}{l}\text { tested for } \\
\text { garment only }\end{array}$ & $\mathrm{x}$ & at normal temperature & $\mathrm{x}$ & & $\mathrm{x}$ & $X$ & \\
\hline Type 6 & & $\mathrm{x}$ & $\mathrm{x}$ & & $\mathrm{x}$ & $\mathrm{x}$ & $\mathrm{x}$ & $\mathrm{X}$ & \\
\hline
\end{tabular}

ism) protection. The ensembles are fully encapsulating the wearer with either a self-contained breathing apparatus (SCBA) worn inside (Type 1a) or self-contained breathing apparatus worn outside (Type 1b).

There are a number of differences between the ISO 16602 and currently revised EN 14325 (revision of 2017) requirements for the 6 garment Types ${ }^{7}$ :

- Classification of property values in ISO 16602 occurs on averages of measured property values while in the current revision of EN 14325 it occurs on the lowest single measured value; but EN property requirements have been readjusted in the EN 14325 to take account of this difference in property values assessment where necessary.

- EN 14325 sets limits for both, permeation breakthrough time and cumulative permeation; ISO 16602 set limits also for both, but contains a completely different assessment of cumulative permeation.

- ISO 16602 has requirements for the assessment of the burst strength and the resistance to penetration by liquids under pressure, which for some CPC Types are optional or obligatory; there are no assessments for these two properties in the current revision of EN 14325.

ISO 27065 (2017) is the CPC standard that outlines performance specifications for pesticide operators. This standard looks at performance requirements for materials, seams, and garments and defines three levels with specified resistance to penetration by pesticide products: Level 1: Low potential risk of contamination from low spray drift landing on the operator; Level 2: Level between 1 and 3 but not so high as to require the use of liquid-tight materials; and Level 3: High-exposure scenarios requiring the use of liquid-tight materials from penetration and permeation ${ }^{8)}$.

\section{European standards and legislation}

European legislation

The provision of protective clothing is covered by two main European Directives ${ }^{9}$, one for users of PPE and one for PPE certification (as of April 2018 PPE need to be compliant to the new European PPE Regulation), the main points of the legislation are given below.

- PPE must be used, as a last line of defence, once an obligatory hazard and risk assessment has been made and the hazards and risks have been reduced by all technical means or by procedures of work organization.

- All PPE must be appropriate for the risks involved, without itself posing any increased risk due to the work environment and conditions.

- The PPE must be provided by the employer free of charge to employees and kept in good condition. Workers must be consulted over PPE, and provided with instructions/training on its use and compatibility with other PPE.

All chemical protective clothing is considered PPE for protection against high risk, i.e. as PPE of "Category III", and therefore requires third party certification and third party annual quality control certification of production to ensure compliance with the technical documentation provided during certification. Each PPE element is also required to be provided with a declaration of conformity to the legislation and user instructions and will be marked with the CE mark and the number of the certifier.

\section{European standards}

EN 14325 provides all the references to the test methods and the classification for all the EN CPC types covering both the mechanical and chemical requirements. All CPC must meet minimum performance requirements.

Various CPC Type standards set higher minimum performance requirements than the minimum limit in EN 


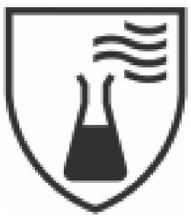

Fig. 2. CPC Symbol.

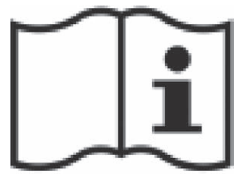

Fig. 3. Reader instructions.

14325, and they contain the Type specific requirements for design, garment tests, product marking and instructions for use. CPC can easily be recognised by being marked with the symbol (Fig. 2), and the CPC markings will provide further information on Type(s) (e.g. Type 3; Type $3 \&$ Type 4), name and publication date of the Type standard(s), name and trade mark, identification of manufacturer, size range, potentially the date of manufacture and other pictograms such as reader instructions for use (Fig. 3) and any other information provided by the manufacturer on the risks against which the CPC protects, chemicals products (including name and approx. concentration) that have been tested and the results or where the information can be obtained, other performance levels (e.g. mechanical), expected shelf life, for reusable CPC the explanation of care pictograms and additional information on cleaning and disinfection, and finally information on size, donning and doffing, use and storage, and limitation of uses.

Type 1 (gas tight)

EN 943-1 Type 1 CPC, gas tight suits, are divided into several subtypes. All Type 1 fabrics are tested against a battery of 15 substances ${ }^{20)}$. The test chemicals represent a wide range of aggressive chemicals. Thus, clothing that meets the requirements according to this standard, may offer protection against a wide range of chemicals. If the breakthrough time for those solvents, gases, acids and bases is not over $30 \mathrm{~min}$, the instructions for use must clearly state that this CPC does not offer protection against continuous exposure to the specific chemical(s).

Type 1a CPC are used in conjunction with a breathable air supply which is both independent of the ambient atmosphere and worn inside the suit e.g. self-contained open-circuit compressed air breathing apparatus. Type $1 \mathrm{~b}$ CPC are used in conjunction with a breathable air supply independent of the ambient atmosphere supplied from or worn outside the suit, e.g. a self-contained open circuit compressed air breathing apparatus. When in Type 1a and $1 \mathrm{~b}$, the facemask is permanently joined to the suit, the garment leak tightness is ensured with a test that measures how pressurised air is held in the suit. If in the Type 1b, the facemask that is not permanently joined to the suit (e.g. facemask that is part of respiratory protective devices (RDP) but not part of CPC), the garment leak tightness is tested with the same pressure test but also with the inward leakage test.

Type 1c CPC is used in conjunction with breathable air providing positive pressure where the suit is also the face piece, e.g. air lines where the wearer breathes from the suit (also called a ventilated suit). Special attention should be given to the adequate selection and fit of respiratory protective equipment. Inward leakage test is also used for Type 1c.

EN 943-2 Types 1a ET and 1b ET are meant for use by emergency teams ${ }^{21)}$. Although EN 943-1 was revised in 2015, EN943-2 failed to be revised. A revision is underway to ensure that both EN 943-1 and EN 943-2 are consistent and that part 2 only covers the ET additions needed in addition to the Type 1 requirements from EN 943-1.

Type 2 (Non gas-tight)

Type 2 CPC still exists in ISO 16602, but no longer exists under EN 943-1. These are not gas tight and a positive pressure of breathable air is provided into the suit e.g. via air lines. The suits can be used against aerosols, sprays or gases, for instance in the manufacture of drugs or other hazardous materials, if the task requires that the employee stands still. Type 2 CPC garment is tested for liquid tightness using an inward leakage test.

Type 3 (jet-tight)

EN 14605 Type 3 CPC (full body and Partial Body (PB) protection) has higher fabric liquid barrier (similar to Type 1 or 2) versus Type $4 \mathrm{CPC}$, and has liquid-tight seams that usually use tape to seal the seam ${ }^{22}$. Type 3 can be used against chemicals that splash under pressure, or where one may lean on contaminated surfaces. The Type 3 CPC garment is tested for liquid tightness by projecting compressed jets of water and surfactant on a human test subject wearing the garment.

Type 4 (spray-tight)

EN 14605 Type 4 CPC (full body and PB protection) has spray-tight seams which are usually taped. Type 4 can be used where there is a risk of small splashes of chemicals (not under pressure); it is not being assessed for protection in case of airborne exposure. The Type 4 CPC garment is tested for liquid tightness by projecting a moderate pressure spray (less than Type 3) of water and surfactant on a human test subject wearing the garment.

Type 5 (airborne solid particulates)

EN ISO 13982-1 Type 5 CPC is full-body protective clothing that provides minimum requirements for resistance to penetration by airborne solid particles ${ }^{23)}$. Type 5 


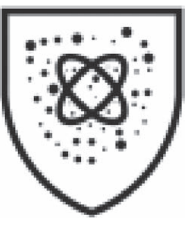

Fig. 4. Radiation particulates.

is applicable only to airborne solid particulates. It is not applicable to other forms of challenge by solid chemicals, e.g. penetration of chemical dust through materials by rubbing or flexing. Type $5 \mathrm{CPC}$ is often used to reduce particulate deposit onto the skin and to lessen the secondary respiratory exposure in asbestos abatement work and other tasks with hazardous dusts (e.g. pharmaceuticals).

The particle leak tightness of the garment is evaluated using EN ISO 13982-2 based on two criteria ${ }^{24)}$ : (1) the total inward leakage (TIL) or overall mean penetration through the suit while worn by test persons in sodium chloride aerosol atmosphere, and (2) the TIL must be less than $15 \%$ for 8 test persons out of 10 .

The EN 1073-2 (see symbol: Fig. 4) is not a Type 5 CPC but very similar and was developed for the nuclear industry and relates to the barrier properties of protective suits against radiation contaminated solid particulates ${ }^{25}$. It does not apply to protection from ionising radiation. It applies the same test method as Type 5 to determine the inward leakage and the barrier efficiency of the garment. There are three performance classes expressed as a 'Nominal Protection Factor' (NPF): Class 1: Lowest particle barrier, NPF 5 to 49; Class 2: NPF 50 to 499; Class 3: Highest particle barrier, NPF $>500$.

Type 6 (mist-tight)

EN 13034 Type 6 CPC (full body and PB protection) provides very limited protection against liquid chemicals $^{26)}$. The fabric is only tested against 4 chemicals for resistance to penetration by liquids and for liquid repellency; this testing is much less stringent than permeation testing and minimum performance requirements have to be met only for two test chemicals. The Type 6 CPC garment is tested by low pressure water spray (only about $10 \%$ volume compared to Type 4).

\section{Outlook for future ISO and EN standards}

Although at a preliminary state, there is an effort to merge the EN and ISO standards related to chemical garment PPE, to realign them and better explain the protection levels for end-users. The intent is to create a modular approach that would add to the "Type 1 through Type 6" designations in order to provide a greater explanation of the protections levels through a new way of garment marking.

US

US legislation

The US government regulation that covers US employer's responsibilities regarding all forms of personal protective equipment (PPE) for use by their employees is 29 CFR 1910.132 (PPE General Requirements) ${ }^{27}$. This regulation requires the employer to assess the workplace to determine if hazards are present, or are likely to be present. If yes, then the employer must select, and have each affected employee use, the appropriate types of PPE. "Appropriate" means that the PPE will protect the affected employee from the hazards identified in the hazard assessment.

With the exception of PPE for respiratory protection, the US government does not specify how PPE must perform. Most performance standards in the US are non-mandatory for PPE suppliers to follow. The 29 CFR 1910.120 (Hazardous Waste Operations and Emergency Response) regulation specifically applies to employees who are exposed or potentially exposed to hazardous substances, including hazardous waste, and who are engaged in specific operations ${ }^{28,29)}$

The OSHA Technical Manual (Section VIII: Chapter 1; Part C) describes 4 levels of protection based on both the respiratory and skin hazards. The design requirements for the 4 levels are summarized in the table below:

Level A PPE design provides the maximum protection available for skin and the respiratory system. A Level A ensemble includes a suit that will fully encapsulate the wearer and his/her breathing apparatus. The suit has a vapor tight construction with gloves attached to the suit, boots or booties attached to the suit and a self-contained breathing apparatus or a supplied air breathing system.

Level B PPE design is a liquid tight ensemble used when the highest level of respiratory protection is needed. A typical Level B ensemble is either fully encapsulated (like a Level A design) or has the SCBA respiratory protection worn outside of the suit. Over-taped seams are most common. The required hand and foot protection can be part of the suit or separate items that are integrated with the suit by the wearer.

Level C PPE design is non-encapsulated clothing (onepiece coverall, hooded two-piece chemical splash suit, chemical resistant hood and apron, disposable chemical resistant coveralls) used with air-purifying respirators for known airborne substance and concentration. Appropriate 
Table 2. CPC's under US OSHA and EPA

\begin{tabular}{|c|c|c|c|c|}
\hline $\begin{array}{l}\text { OSHA/EPA } \\
\text { Level }\end{array}$ & Skin Hazard & Garment Design & Respiratory Hazard & Respiratory Protection \\
\hline A & Vapor, Liquid or Particle & Encapsulating \& air-tight & \multirow{2}{*}{$\begin{array}{l}\text { IDLH or low } \mathrm{O}_{2} \text { or unknown } \\
\text { chemicals or unknown concentra- } \\
\text { tion or APR not effective }\end{array}$} & \multirow{2}{*}{$\begin{array}{c}\text { Open- or Closed-circuit SCBAor } \\
\text { Supplied air respirator (Airline) } \\
\text { with escape Bottle }\end{array}$} \\
\hline B & \multirow[b]{2}{*}{ Liquid or Particle } & Encapsulating \& non-air-tight & & \\
\hline $\mathrm{C}$ & & \multirow[t]{2}{*}{ Not encapsulating \& not air-tight } & $\begin{array}{c}\text { Chemical \& concentration } \\
\text { known; APR effective } \\
>19.5 \% \mathrm{O}_{2}\end{array}$ & APR or PAPR \\
\hline D & Nuisance & & \multicolumn{2}{|c|}{ No Respiratory Hazard } \\
\hline
\end{tabular}

CPC are categorized from high to low, Level A-D. IDLH (Immediately Dangerous to Life or Health), APR (Air Purifying Respirator) PAPR (Powered Air Purifying Respirator)

chemical protective gloves and boots are also employed as needed.

Level D PPE design is work clothing used for nuisance contamination (i.e. non-protective). It requires only coveralls and safety shoes/boots. No respiratory protection is required. Other PPE used is based upon the situation (types of gloves, etc.). Level D designed PPE should not be worn where respiratory or skin hazards do exist.

US standards

Other than respiratory protective devices, all other testing of PPE used in the US is done on a voluntary basis by the manufacturers. For Respiratory Protective Devices, 42 CFR Part 84 requires that all respirators be tested. Respirator testing is conducted by CDC-NIOSH-NPPTL. There are several NFPA standards that are used by manufacturers to claim performance of their chemical PPE. Most of these standards were developed for emergency response and HazMat situations, but could also be applicable to industrial chemical hazard protection.

NFPA 1991 "Standard on Vapor-Protective Ensembles for Hazardous Materials Emergencies and CBRN Terrorism Incidents" meets the requirements of EPA "Level A" suits ${ }^{30)}$. It is similar but not identical to the EN 943-2 Emergency Teams standard. NFPA 1991 has a number of increased requirements versus EN 943-2, such as permeation on a battery of 27 chemicals including chemical warfare agents, inflation/pressure testing, inward leakage testing, and a $3 \mathrm{~s}$ flame impingement test. NFPA 1991 covers the requirements for Class $1 \mathrm{CBRN}$ protective ensembles and ensemble elements. NFPA 1991 also permits the suit to be tested against an optional flash-fire escape battery of tests and an optional liquefied gas battery of tests.

NFPA 1992 "Standard on Liquid Splash-Protective Ensembles and Clothing for Hazardous Materials Emergencies" meets the requirements of EPA Level B for suit design $^{31)}$. It is similar to the ISO 16602 Type 2 and Type $3 \mathrm{CPC}$, rather than using permeation it uses penetration testing which is run on a smaller battery of 7 chemicals. NFPA 1992 also specifies the testing of the suit against an optional flash-fire escape battery of tests.

NFPA 1994 "Standard on Protective Ensembles for First Responders to CBRN Terrorism Incidents" specifies 3 performance classes, i.e. Class 2, Class 3 and Class 4 (Class 1 protection is covered by NFPA 1991) ${ }^{32}$. These 3 classes of CBRN protective ensembles for First Responders offer 2 levels of chemical protection (Class 2 and 3) and 1 level of particle protection (Class 4). Class 2 and Class 3 chemical protection is based on permeation resistance to 7 chemicals and design validation against vapor inward leakage. Class 3 \& Class 4 garment materials must provide specific levels of moisture vapor transport. Class 3 is similar to Class 2, but Class 3 is tested against a lower chemical concentration for permeation and has higher requirements on comfort (total heat loss). Class 4 provides particulate protection assessed using a whole garment particulate inward leakage test. Class 4 also has requirements on comfort (total heat loss). NFPA 1994 Class 2, 3, and 4 must also pass for biological protection using ASTM F1671 133 .

Development is underway for a new selection, use, care, and maintenance document which will be called NFPA 1891. This document will aid users to understand how to properly select the most appropriate NFPA 1991, 1992, and/or 1994 garment to meet their protection needs.

\section{Other}

Brazil

Brazil has a similar PPE certification scheme as Europe. PPE for chemical protection can only be offered for sale or use with a Certificate of Approval (CA) issued by an official national body under the Ministry of Labor and 
Employment. CA certified garments need to be worn. Brazil applies ISO 16602 and ISO 27065 or equivalent standards.

Japan

Japan legislation on Industrial Safety and Health requires that PPE is worn in case of potential exposure to hazardous substances. The Japanese standard JIST 8115 is equivalent to the International Standard ISO 16602, except some modifications.

\section{China}

The Chinese Law of the People's Republic of China on Work Safety (Order of the President No. 70) sets general requirements on worker safety and prevention. The Regulations on Labour Protection in Workplaces Where Toxic Substances Are Used requires the employer to:

- provide occupational health training before and give regular refresher trainings,

- supervise employee on regulations and operating rules, and

- correctly use of PPE against occupational health hazards.

The No. 54 of Chinese Labour Law requires the employer to provide workers with safe \& hygienic working conditions and requisite PPE in conformity with the state provisions, and carry out regular health examination to employees who are engaged in hazards operations. The China Compulsory Certification (CCC) system and the CCC mark are compulsory for many products imported, sold or used in China. It started to be in effect from 2015 for emergency responders' Chemical Protective Clothing. (Previously, the LA mark was the compliance certification for PPE manufacturer in China). The manufacturers can get the certification by passing the performance testing based on for example the standard GA 770 and plant audit. GB standards

GB 24539 Performance requirements of chemical protective clothing. This is the general chemical standard, similar to ISO 16602; it is not mandatory.

GB 24540 Protective clothing against liquid acids and alkalis. Production license is required for manufacturer (adopted by LA certification).

GB/T 24536 Protective Clothing Selection, Use, Maintenance of chemical protective clothing.

GB/T 29511 Chemical protective clothing against solid particulates. It is not mandatory.

GA 770 Chemical protective ensemble for firefighters. This is the mandatory standard for Chemical Protective
Clothing for emergency responders (specifically for firefighters) providing a high-level of protection in Hazmat accidents.

Korea

Occupational Safety and Health Act 2016, Article 34, describes that the ministry of employment and labour may determine and publish safety certification standards for PPE. Enforcement Decree of the Occupational Safety and Health Act 2017, Article 28, defines PPE are subjected to safety certification. Public Announcement by the Ministry of Employment and Labor, 2014-46 set performance requirements and test methods for PPE. In addition to these, Chemical Control Act 2015, Article 5 and Article 14 require that safety managers appointed by the employer supervise the selection of PPE and ensure that workers under his supervision have received instructions and training and use the KOSHA certified PPE.

The performance requirements for chemical protective clothing in Public Announcement by the Ministry of Employment and Labor, 2014-46 are mostly same as European standards. However, there's some national modification for Type 1 garment. Type 1 must have attached boots and Type 1-ET shall be reusable. Type 2 will be eliminated by following European standards at next revision.

\section{Overview about Selection of CPC - A Life Saving Choice}

The selection of chemical protective clothing (CPC) is a step by step approach that starts with a broad risk assessment for a defined work situation. This section will provide several simplified steps to select the appropriate CPC. A detailed analysis of the work environment is essential in making the right choice of the most effective protective clothing that balances protection and comfort while being compliant to the norms and regulations. The main purpose of the hazard and risk assessment is to identify and then to eliminate or minimise worker exposure to residual hazards and risk.

\section{Risk assessment}

A risk assessment is a combination of likelihood of accidents (never, unlikely, possible, likely, multiple exposures likely, continuous) and severity of consequence (no effect, discomfort, treatable injury, debilitating injury, death). The risk assessment should identify all hazards and information should be available on the safe level of these hazards. 


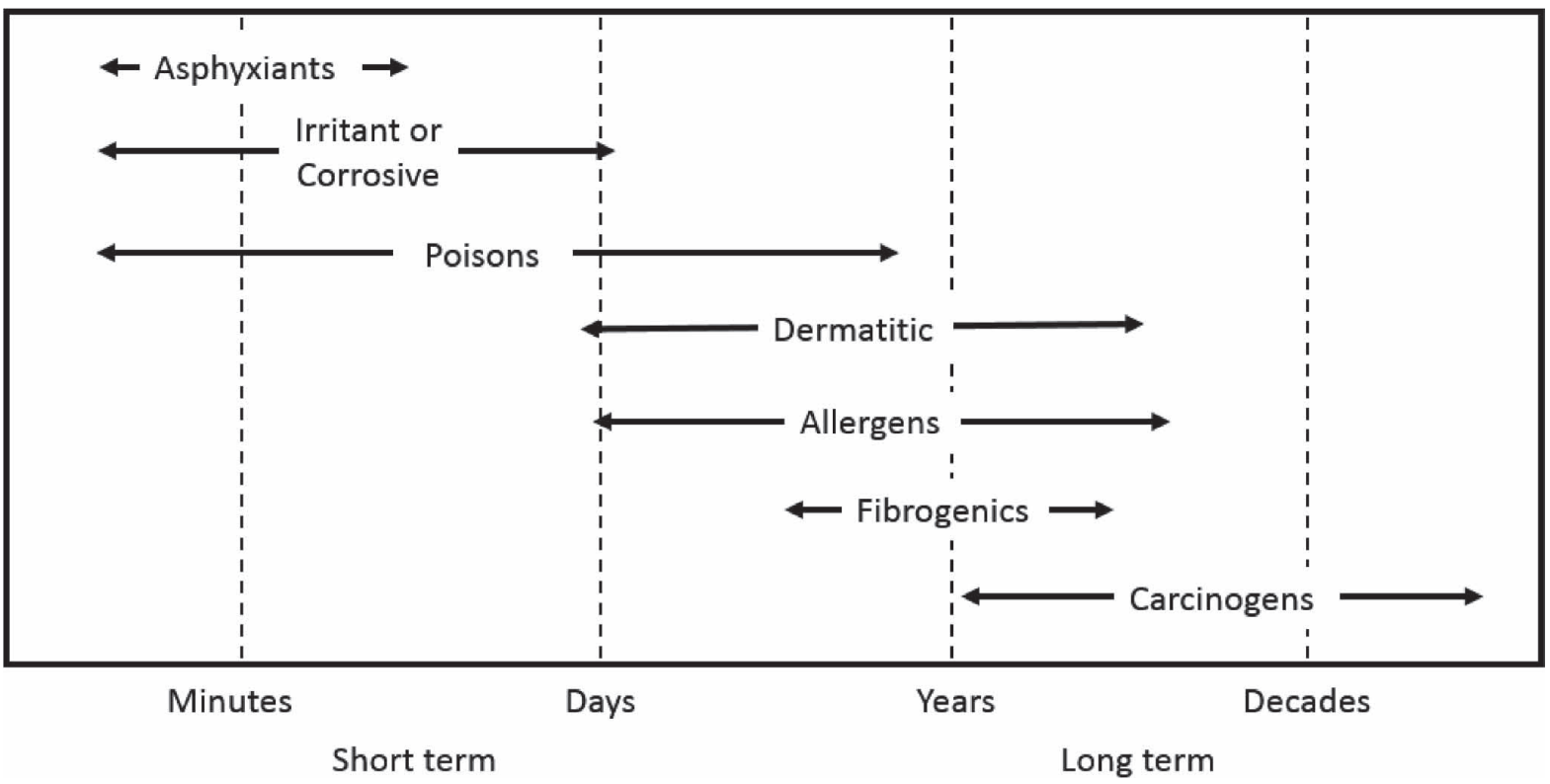

Fig. 5. Short versus long term effect of chemical exposure.

The assessment should be a realistic worst-case scenario. Remember an accident is rarely due to a single large failure, but often due to a "domino effect" combination of small errors. The risk to the worker may concern their whole body or part of their body. The chosen PPE should cover all body parts that are at risk.

\section{Work environment}

The first step in a risk assessment is usually to follow the process or understand the specific work location in which the exposure(s) may occur. The exposure is defined by duration (e.g. seconds, hours), frequency (e.g. continual, intermittent or accidental contact), amount and the force of the exposure, and the direction of the exposure (to which part of the body).

Also, existing historical information on exposure data and incident records, existing PPE used can help to define or refine the PPE needs. Finally, before PPE is chosen, all risk mitigation and engineering and administrative controls should be applied.

Most important are still the human factors such as:

- how many workers are affected,

- work rate, work load, the temperature and humidity of the work area, age and degree of fitness of workers as these are all parameters which determine the length of time before building up of excessive heat stress,

- the need for vision and mobility.

These factors are used to decide the chemical barrier needed, in addition to information about the chemicals and their toxicity.

Chemicals

What is the specific chemical risk considering there are many thousands of known chemicals? Is it a gas, vapour, liquid, particulate? Can the chemical change state (e.g. from liquid to vapour)? What are the concentration levels of the chemical(s)? Is the hazardous chemical in pure form or a mixture of several chemicals? Many of the key properties of a specific chemical that are important to CPC selection can be found in the safety data sheet (SDS), such as:

- Physical properties: vapour density, vapour pressure, flash point, boiling point, melting point, freezing point, solubility, state, specific gravity

- Toxicity: corrosivity, exposure limits, risk phrases.

\section{Toxicity}

Knowing the toxicity or consequences of short or longterm exposure to the hazard is essential. Data on the garment's fabric, seams, and closure system on penetration and permeation testing will indicate the permitted time of exposure before reaching human toxicity. Toxicity is dependent on the mode of interaction with the human body, some chemicals are more toxic to skin, others by inhalation, and the dose or concentration of the uptake into the body is important. Some chemicals have a short-term effect, others have a long-term effect or more insidious effect on the organism as it is less visible (see Fig. 5).

Exposure to chemicals occurs through three routes: 
- Inhalation: protection is primarily provided through respiratory protection, but CPC are important when hazardous particles and volatile liquids are involved because the CPC can limit cross-contamination. If a respiratory hazardous particle collects on a worker's skin or clothing, that hazardous particle can later transfer to the worker's vehicle or home, thereby bringing a toxic material home unknowingly.

- Ingestion: is not just "eating" the chemical, but also dust or particulates that become trapped in mucus on respiratory track walls.

- Skin Contact: Skin damage when in contact with corrosive substances or allergens may cause irritation/ inflammation leading to secondary microbial/fungal attack. CPC can also protect from chemical absorption through the skin into the blood stream, as blood flows close to the skin.

Assessment of needed protection other than chemical

Other than the toxicity of the chemicals other factors should be taken into account that can be related to overall risk. Here are a couple of examples:

- rough terrain or workplace with a risk of puncture, cuts or abrasions. An excellent barrier is only worthwhile if it withstands working conditions and remains intact for the duration of the task.

- the use volatile flammable substance may define a need for anti-static properties to avoid a spark igniting or creating a chemical explosion,

- heat and flame protection in case of hot surface, liquids or steam, protection against flash fires or electric arc,

- Biohazards - protection against infective agents (virus/bacteria and blood borne pathogens such as Ebola, AIDS virus, hepatitis). This protection is covered by multiple standards:

- EN 14126 - infective agents including microorganisms (liquid, aerosol, dust, particulates) ${ }^{34)}$

- ISO $16603{ }^{35)}$ (or ASTM F1670) - blood borne pathogens and synthetic blood

- ISO 16604 ${ }^{36)}$ (ASTM F1671) - blood borne pathogens and Phi-X174 bacteriophage

○ ISO 22610 ${ }^{37)}$ (EN ISO 22610) - contaminated liquids

○ ISO 22612 ${ }^{38)}$ (EN ISO 22612) - contaminated solid particulates

- Protection against linting or particulate shedding for production of products such as electronics or pharmaceuticals, special medical or laboratory environments, etc., where clean room conditions are required. The human body emits over 250,000 submicron particles $(<0.05$ microns $)$ every minute. In the clean room area, goal is to keep these particles from escaping and contaminating the product or environment in which one is working as well as prevent contamination of the worker in areas where harmful chemicals are present. Concerns with clean room garments also include breathability, and their ability to be reliably disinfected or sterilized.

\section{PPE Selection}

The CPC, as the last line of defence, must not be the weakest link in protecting the worker. Therefore, during the selection, the purchaser should ask for as much detail possible on the $\mathrm{CPC}$ being considered.

\section{Type of CPC}

The focus is going to be skin contact as CPC are intended to protect parts of the skin. In cases of a mist, gas or particulates, the imperviousness of the CPC becomes important as it may become part of an assembly of PPE (eyes, face, respiratory protection). The direction and the intensity of the exposure if it is a mist, spray or jet is important to choose the CPC (See Fig. 6), and finally, the duration of potential exposure to the chemical(s). It is not just the "Type" as defined by ISO 16602 or EN 14325, the fabric and the seams provide valuable additional information on the offered protection.

Fabrics

There are various chemical resistant polymers or composites used in protective clothing (including gloves) such as natural rubber, neoprene, PVC, nitrile, PVA, butyl, Viton $^{\circledR}$, and laminates.

In general, re-usable garments are more durable in their construction, but they have their weakness too: (1) uncertainty of barrier capability after contamination, (2) more inspection to ensure leak tightness in case of re-use, (3) comfort.

No matter what the brand, the majority of limited-use protective clothing products can be classified into a small number of broad fabric technologies. Although they may look the same in garment form, it is very important to realise that, in practice, these different technologies exhibit widely varying performance attributes.

Various laminated fabrics provide innovative fabric range comprising multiple barrier layers to bring lightweight protection to specific or multiple risks (chemical, biological, heat and flame and other), durability and 


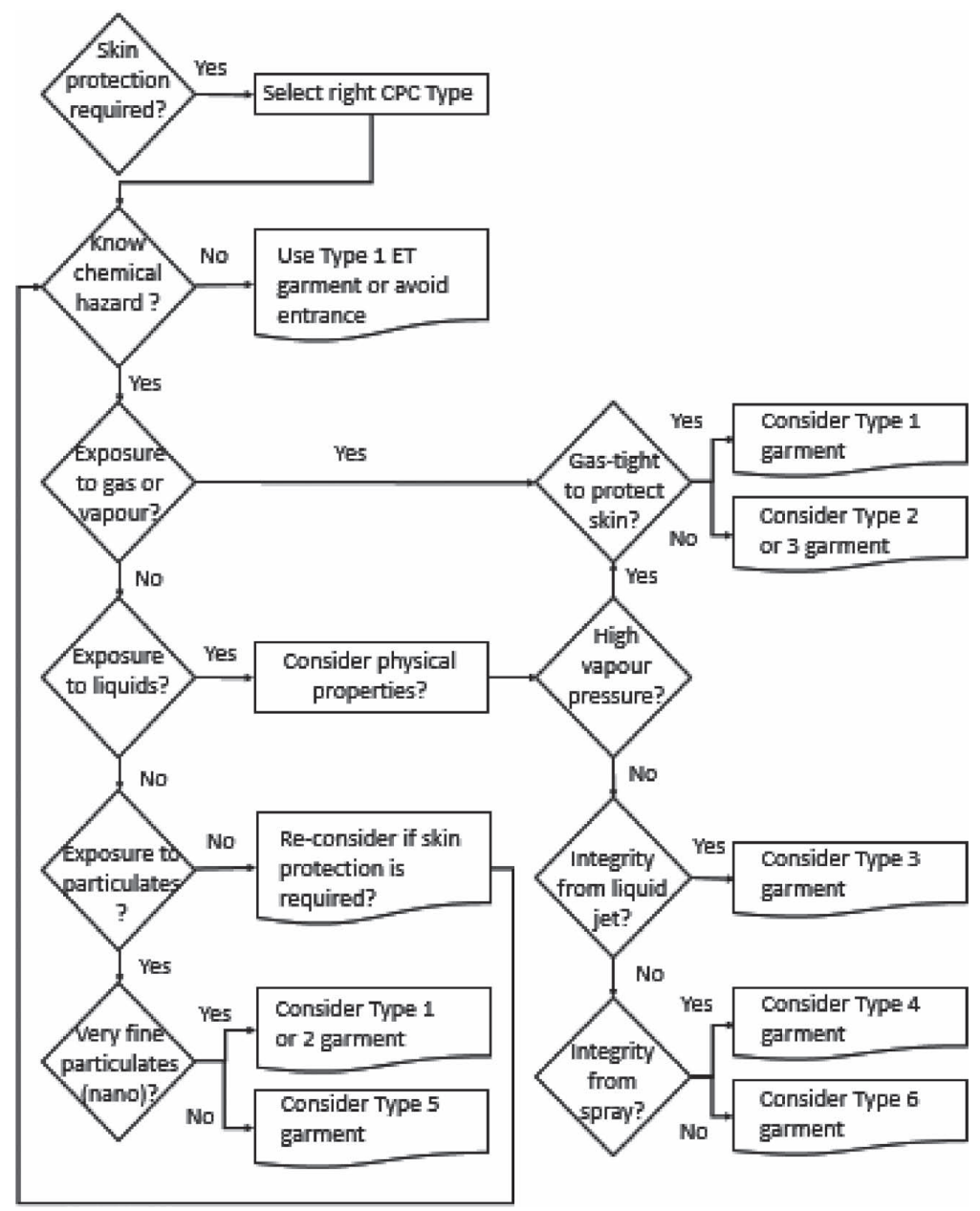

Fig. 6. Type 1 through Type 6 selection process.

comfort. These may contain various thin layers of materials (e.g. polymer coating(s), polypropylene or polyester layer(s), non-woven materials, elastomers such as Viton ${ }^{\circledR}$ ) to provide the characteristics desired from a protection level.

Tyvek $^{\circledR}$ fabric, manufactured by a flash-spinning process into a non-woven, is made of strong, continuous, and high-density polyethylene fibres. The fibres are thermally bonded into a tight, homogeneous and soft fabric that is intrinsically breathable, does not shed fibres ('linting') and has inherent barrier properties i.e. not reliant on any applied coating or layer. This unique combination of barrier protection and inherent breathability makes it ideal for a wide range of protective garment applications.

Microporous films (MPF) fabrics are a bi-laminate material comprising a thin microporous film bonded to a spunbound polypropylene base. They offer limited durability since all barrier protection is lost when the thin protective film layer is abraded. They are also less breathable than other fabrics which implies poor wearer comfort.

The performance of Spunbound/Meltblown/Spunbound (SMS) fabric relies on a meltblown polypropylene layer sandwiched between two open polypropylene layers. This inner polypropylene layer functions as the main filter for particles. However, SMS fabrics tend to suffer from limited durability and relatively limited liquid barrier performance due to their relatively open fibre structure. Therefore, SMS is appropriate for very basic protection and as a dirt barrier.

Tightly woven, for example polyester/cotton, fibre blends with a repellency coating added can meet ISO 16602 Type 6 barrier requirements although they generally provide more comfort. But once the repellency coating is worn off or washed away the protection is lost.

Garment seams and closures

Not only should a CPC garment to be manufactured using the best barrier fabric, but the seams and closures are critical elements. Many different seam configurations exist that provide strength and impenetrability characteristics 


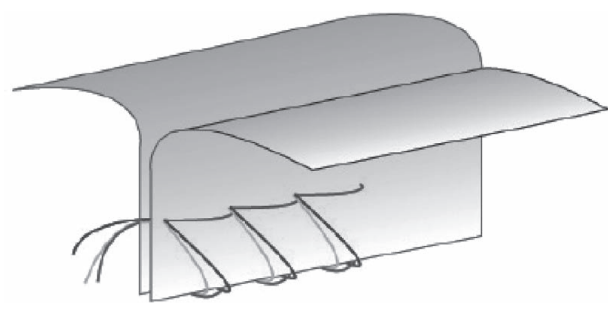

Fig. 7. Stitched seam configuration.

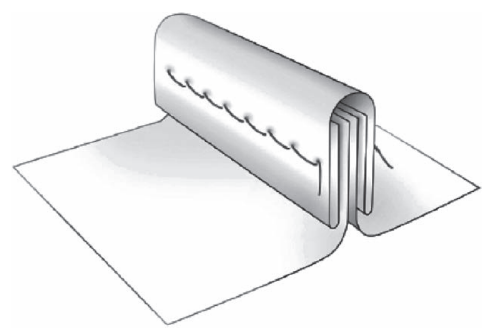

Fig. 8. Bound seam configuration.

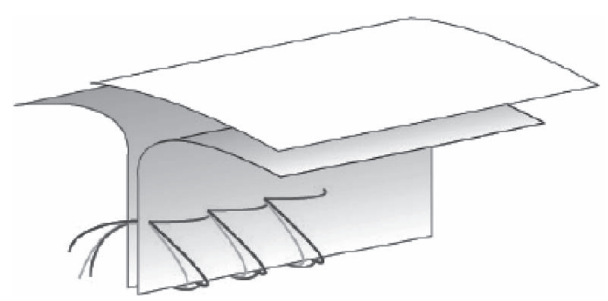

Fig. 9. stitched and taped seam configuration.

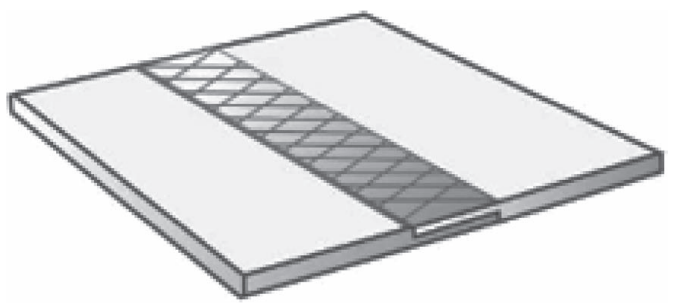

Fig. 10. Welded seam configuration.

for different hazards and uses. Here are some examples in order of increasing strength and imperviousness. The simplest is the stitched seam (see Fig. 7) used mostly for Type 5 and 6 garments. The bound seam (see Fig. 8) provides better imperviousness than a stitched seam but not equal permeation as the fabric alone because needles holes are present. Finally, stitched and over taped seams (see Fig. 9) or welded seams (see Fig. 10) provide equal or better barrier than fabric and are often used for Type 1,2, 3 and 4 garments.

The same considerations apply to closure systems such as zippers and coverings, and to garment interfaces and boundaries in the neck, hood, wrist and ankle areas.

Chemical protective performance requirements

Penetration/repellency

Penetration is the physical process of a chemical flowing on a bulk level through closures, porous materials, seams, pin holes, or other imperfections, including defective seams or inadequately sealed closures. The test used for penetration/repellency in the standard for Type 6 CPC drops a small quantity of liquid onto the surface of the fabric which is laid in an inclined gutter. The liquid is allowed to run off (this is the repellency quantity) and the quantity that penetrates the material is absorbed by an absorptive fabric between the test fabric and the gutter. The weight increase of the absorptive fabric is the measure for the quantity of the chemical which penetrated through the test fabric. To fulfil Type 6 requirements, for one of the listed test chemical in EN 13034, the penetration must be less than $5 \%$.

Permeation

Permeation is the molecular process by which a chemical moves through the barrier material through three steps: adsorption (uptake), diffusion through polymer, and desorption or exposure in the measuring medium or on the skin. Permeation is temperature dependent, it increases with increased temperature. Permeation through continuous contact is a worst-case condition and it's required for Types 1, 2, 3, and 4 CPC.

There are two permeation test endpoints: (1) breakthrough time (2) cumulative permeated mass

- breakthrough detection time is the elapsed time between initial contact of the chemical on the outside of the CPC and the time at which the chemical is detected in the collection medium in contact with the inside surface of the CPC. The breakthrough time is always specific for the pair: CPC material and chemical. In CPC standards, it is not the breakthrough detection time which is used for the classification of the permeation resistance of materials, but a normalised breakthrough time, i.e. the time it takes for the permeating chemical to reach a specified permeation rate. In EN standards, the breakthrough time to reach the permeation rate of $1.0 \mu \mathrm{g} / \mathrm{cm}^{2}$.min is reported and used for the classification of the performance into 6 protection classes (lowest being $>10 \mathrm{~min}$ and the highest $>480 \mathrm{~min}$ ). In US standards, breakthrough time to reach permeation rate of $0.1 \mu \mathrm{g} / \mathrm{cm}^{2}$. min is reported and used for classification.

- Cumulative permeated mass is the total amount of 
chemical that permeated through the material in a given period of time (reported in $\mu \mathrm{g} / \mathrm{cm}^{2}$ ).

Both ways of expressing the result of permeation testing are valuable.

The first, i.e. the normalised breakthrough time, provides an indication of how long it takes for a chemical to permeate through up to a specified permeation rate. This is not the same as the safe use time of the clothing, as the amount of chemical permeated through the material at a time equal to the normalized breakthrough time may - depending on the toxicity of the chemical - already be harmful to the wearer; in such a case the safe use time is shorter than the normalized breakthrough time. But the normalized breakthrough time is a tool to compare products and to provide a warning about totally unsuitable products.

Testing for cumulative permeation provides the total mass of the permeated chemical over a specific period of time. This together with the toxicity of the chemical can provide information to determine a safe use time for the CPC.

\section{Comfort}

Appropriate protection is critical, and so is comfort as it contributes to protective clothing use compliance by wearers. Reduced comfort will reduce a person's efficiency and with heat stress can induce physiological harm to the wearer. There are many comfort factors, most frequently cited in wearer trials include ease of movement when bending/stretching, weight of the garment, feel on the skin, and breathability of the garment. Garments with both air permeability (Gurley Method ISO 5626-5) or air permeability (ASTM F737), and vapour permeability (EN ISO 11092) will be more comfortable, but garments with enhanced comfort properties will offer a lower particulate or liquid chemical barrier.

\section{Compatibility}

Don't forget that CPC is rarely used on its own. Rather it is part of an ensemble - therefore when using other PPE (boots, gloves, helmets, goggles, face-shield, visor, RPD), the compatibility or interoperability must be assessed with respect to appropriate chemical protection, but also related to freedom of movement, visibility, etc.

\section{Supplier consideration}

The evaluation of the manufacturer of CPC that is going to provide the protection that your workers will depend on requires due diligence on the employer's part to ensure that certified to ISO 9001.

- the manufacturer's ethical standing and environmental record is good, and that it can certify that the protective garments are free from hazardous materials or banned ingredients, free from SVHC's (REACH compliant) and not include skin allergens or sensitizers.

- service and business integrity, accreditations, ISO 9001 and ISO 14001. The manufacturer should provide a high level of pre- and after-sales service and support ideally including training programmes, testing services, selection tools, risk-analysis guidance and permeation data.

- the delivery that can be made from stock, globally when required (e.g. logistics)

- the information from supplier that either comes with the product or is provided by the supplier by other means is complete to make the selection e.g. mechanical properties, permeation databases on chemicals additional to those required for testing. Do they provide additional information such as web-based tools (see links to company databases ${ }^{39)}$ ) or on-site risk assessment support? Do they provide training? Do they answer addition technical questions through a phone service?

Understand product limitations that various suppliers may have through checking:

- whether the garments provide the correct fit and whether they are available in a full range of sizes to suit different physical and gender characteristics. A garment must have a non-restrictive, ergonomic fit, be compatible with other PPE items, but not too bulky as to present undue risk of snagging or tripping.

- In addition to checking the supplier, it is also important to check the product characteristics to see if there are some limitations of use.

- the user instruction provided with the CPC should be a useful source of information on the correct use of the product and any restrictions in usage or compatibility with other PPE.

- Ease of use should be assessed: Is donning and doffing well thought through without damaging the CPC? Check if additional taping is required for the mask, cuffs, ankles? Are there other requirements such as grounding needed?

Wearer trials

Wear trials of the CPC being considered can be valuable before making a large purchase. The purpose is to ensure:

- compatibility with other PPE,

- that it functions under the expected operating condi- 
tions (e.g. durability),

- that the wearers' assessment regarding fit and extent of adjustability, mobility, ease and speed of donning and doffing, comfort, etc. are obtained.

\section{Garment in Use}

A chemical protective garment is a piece of technical equipment that requires correct use, care and maintenance. Poor use or care means poor protection.

It is important to document the selection process, the risk assessment, the information collected on the garments, wear trials, and decisions that were used in the choice of the specific garment with the pros and cons of the choice. Any negative attributes of the garment that affect the protection of the worker needs to become part of the training. It is also important to evaluate and monitor the PPE in the work place over time to ensure that protection needs continue to be met.

\section{Training}

There are a number of aspects to consider: (1) the workplace and employees (2) donning and doffing (3) inspection pre- and post-use.

Take into account for the training the exposure issues in the workplace, the health and safety program, the expected chemical exposures and the exposure limits and their effect (visible and invisible) on the person to reinforce the usage of the CPC. Take into account also the number of employees that need to be trained (normally, the more employees the less hands-on the training). Also important is to understand whether current practices and procedures are followed (e.g. personal hygiene, PPE worn while eating/smoking, etc) and whether the previous PPE was worn correctly or not. Consider using a full wearer training with a number of exercises. The training should also include the periods of work and rest, rehydration to avoid heat stress. Issues of self-rescue or rescue assistance need to be addressed and planned to avoid injury for carrying out the rescue.

Each individual part of the PPE should be inspected before it is worn. For CPC, this includes checking for defects in: assembly, garment and components, accessories, interfaces, closures, sufficiency of ventilation rate (gas-tight clothing).

Training on safe donning procedures should be completed including for the taping of the garment closures and/or of connections between various items of PPE, and including specific movements to ensure good fit, so that the garment does not crack or rip during usage.

Training on doffing for both the wearer and any assistant to avoid self- and cross-contamination. A quick decontamination could include a rinse procedure (if the garment is sufficiently impervious to avoid contamination being pushed through during rinsing).

The training should be supported with regular refresher courses. Records should be kept for trainees, trainers and training content.

\section{Inspections}

For all garments inspections should be done prior to each use. For a reusable garment, a regular schedule should be put in place to inspect the garment based on the manufacturer's recommendations. These should take place at least after doffing, after cleaning or repairs. Records must be kept for reusable garment of all inspection procedures containing item identification number, date of inspection, person conducting the inspection, results, and unusual findings.

The following should be inspected as these factors can cause inacceptable ageing and reduction of the protective performance:

- Any physical damage such as cracks in the fabric, seams (e.g. missing stitches or loss of taping/seal), integrity of closure system, or any signs of wear and tear (e.g. abrasion, flexing, pressure/strain, deterioration due to UV radiation)

- Contamination, cleaning and decontamination (see below)

- Repair (see below)

- Poor storage or exceed shelf life (see below)

\section{Contamination, cleaning and decontamination}

The instructions for use of protective clothing contain guidance on cleaning and disinfection or decontamination. Hygienic cleaning should be distinguished from decontamination. The hygienic cleaning is to avoid spreading of disease, removal of unpleasant odours, but also ensure that no residues of cleaning products remain. The decontamination is to remove dirt, chemical or biological contamination. $\mathrm{CPC}$ has to be discarded or can be reused after decontamination depending on the intended use specified by the CPC manufacturer.

In addition, for CPC made of repellency treated materials, there should be information about whether and when reapplication of repellency treatment is necessary.

During decontamination, the chemical contaminants are removed or neutralized from the surface of the chemical 
protective clothing. Proper decontamination may permit the reuse of protective clothing that is labelled as reusable. Decontamination can be done using a variety of technics - physical (pressurised water, scrubbing), chemical (inactivate the contaminant) or combination - but shall be done always in accordance with manufacturer's instructions.

The effectiveness of the decontamination should be checked for any signs of degradation:

- visual: weight change, swelling, stiffness, discoloration, delamination, hole/rip/tear.

- odour

\section{Repairs}

For reusable garments, repairs should be carried out only if the garment will be again in good working order (potentially include any tests such as for gas tightness). If the repair cannot ensure good working order, then the garment should be disposed of.

Ensure that the garment is decontaminated before making repairs and that all repair work is completed according to the manufacturer's instructions.

\section{Storage}

The storage must be arranged to prevent damage to the garments such as exposure to sunlight, dust, moisture (too much or too little), or extreme temperatures. Mechanical damage during transport or storage, or storing in the same room as chemicals should be avoided. User Instructions should also provide information on shelf life (how long the $\mathrm{CPC}$ can be stored and used if not damaged).

\section{Disposal}

CPC no longer fit for use based on the remarks made above, notably under the section Inspections, should be discarded based on local laws and regulation taking into account any chemical contamination.

\section{Acknowledgements}

All of the views expressed in this paper are those of the author. I would like to acknowledge the contribution of my colleagues at DuPont for their support in providing this overview.

\section{References for futher information/Links:}

1) Bender and Eisenbarth: Hazardous chemicals - Control and Regulation in the European Market, 2007 by Wiley-VCH

2) Patnaik: A Comprehensive Guide to the Hazardous Proper- ties of Chemical Substances, 1999 by John Wiley \& Sons

3) Forsberg and Mansdorf: Quick Selection Guide to Chemical Protective Clothing, 2007 by John Wiley \& Sons

4) Forsberg and Mansdorf: Chemical Protective Clothing Performance Index, 1999 by John Wiley \& Sons

5) ISO 16602: Protective clothing against chemicals - Classification, labelling and performance requirements

6) ISO DIS 17723-1: PPE ensembles for firefighters undertaking hazardous materials response activities - Part 1: GasTight, vapor protective ensembles for emergency response teams ("Type 1ET")

7) EN 14325: Protective clothing against chemicals. Test methods and performance classification of chemical protective clothing materials, seams, joins and assemblages

8) EN ISO FDIS 27065 Protective clothing — Performance requirements for protective clothing worn by operators applying liquid pesticides and for re-entry workers

9) EU Directives: Directive 89/656/EEC of 30 November 1989 on the minimum health and safety requirements for the use by workers of personal protective equipment at the workplace; Directive 89/686/EEC on the approximation of the laws of the Member States relating to personal protective equipment; Regulation EU 2016/425, on personal protective equipment

10) EN ISO 6529 Protective clothing - Protection against chemicals. Determination of resistance of protective clothing materials to permeation by liquids and gases

11) EN ISO 6530 Protective clothing - Protection against liquid chemicals. Test method for resistance of materials to penetration by liquids

12) EN ISO 12947-2: Textiles - Determination of the abrasion resistance of fabrics by the Martindale method - Part 2: Determination of specimen breakdown

13) EN 530: Abrasion resistance of protective clothing material — Test methods

14) EN ISO 7854: Rubber- or plastics-coated fabrics - Determination of resistance to damage by flexing

15) EN ISO 9073-4: Textiles — Test methods for nonwovens - Part 4: Determination of tear resistance

16) EN ISO 13934-1: Textiles - Tensile properties of fabrics - Part 1: Determination of maximum force and elongation at maximum force using the strip method

17) ISO 13996: Protective clothing — Mechanical properties - Determination of resistance to puncture

18) EN 863, Protective clothing - Mechanical properties Test method: Puncture resistance

19) EN ISO 13935-2: Textiles - Seam tensile properties of fabrics and made-up textile articles - Part 2: Determination of maximum force to seam rupture using the grab method

20) EN 943-1: Protective clothing against liquid and gaseous chemicals, including liquid aerosols and solid particles, Part 1: Performance requirements Type 1 (gas-tight)

21) EN 943-2: Protective clothing against liquid and gaseous chemicals, including liquid aerosols and solid particles. Part 
2: Performance requirements for 'gastight' (Type 1) chemical protective suits for emergency teams (ET)

22) EN 14605: Protective clothing against liquid chemicals. Performance requirements for clothing with liquid-tight (Type 3) or spray-tight (Type 4) connections, including items providing protection to parts of the body only (Types $\mathrm{PB})$

23) EN ISO 13982-1: Protective clothing for use against solid particulates. Part 1: Performance requirements for chemical protective clothing providing protection to the full body against airborne solid particulates (type 5 clothing)

24) EN ISO 13982-2: Protective clothing for use against solid particulates - Part 2: Test method of determination of inward leakage of aerosols of fine particles into suits

25) EN 1073-2: Protective clothing against radioactive contamination Part 2: Requirements and test methods for non-ventilated protective clothing against particulate radioactive contamination

26) EN 13034: Protective clothing against liquid chemicals. Performance requirements for chemical protective clothing offering limited protective performance against liquid chemicals (Type 6 and Type PB equipment)

27) OSHA 29 CFR 1910.132: Occupational Safety and Health Standards: Personal Protective Equipment

28) OSHA 29 CFR 1910.120: Occupational Safety and Health Standards: Hazardous waste operations and emergency response.

29) National Fire Protection Association: Standards on Chemical Protective Clothing - History Evolution and Current Criteria, 2013 by NFPA

30) NFPA 1991: Standard on Vapor-Protective Ensembles for Hazardous Materials Emergencies and CBRN Terrorism Incidents

31) NFPA 1992: Standard on Liquid Splash-Protective Ensembles and Clothing for Hazardous Materials Emergencies

32) NFPA 1994: Standard on Protective Ensembles for Chemical/Biological Terrorism Incidents

33) ASTM F1671: Standard Test Method for Resistance of Materials Used in Protective Clothing to Penetration by Blood-Borne Pathogens Using Phi-X174 Bacteriophage Penetration as a Test System

34) EN 14126: Protective clothing. Performance requirements and tests methods for protective clothing against infective agents

35) ISO 16603: Clothing for protection against contact with blood and body fluids - Determination of the resistance of protective clothing materials to penetration by blood and body fluids - Test method using synthetic blood

36) ISO 16604: Clothing for protection against contact with blood and body fluids - Determination of resistance of protective clothing materials to penetration by blood-borne pathogens — Test method using Phi-X174 bacteriophage

37) EN ISO 22610: Surgical drapes, gowns and clean air suits, used as medical devices, for patients, clinical staff and equipment - test method to determine the resistance to wet bacterial penetration

38) ISO 22612 Clothing for protection against infectious agents - Test method for resistance to penetration by biologically contaminant dust through protective clothing materials

\section{Links company databases}

DuPont - Europe: http://www.safespec.dupont.co.uk/safespec/ selector/en/home.html

DuPont - US: http://www.safespec.dupont.com/safespec/ selectorHome

DuPont- Asia Pacific: http://safespec2.dupont.com/safespec/ chemical/en/search.html

3M: http://www.3m.co.uk/3M/en_GB/company-uk/3mproducts/ /All-3M-Products/Safety-Products/?N = 5002385 $+8711017+8711415 \& \mathrm{Ntt}=$ protective + coverall\&rt $=\mathrm{rs}$

Ansell: http://www.ansell.com/en/Products/Protective-Clothing/ Chemical-Protective-Suits.aspx

Microguard: http://www.microgard.com/results.asp

Honeywell: www.honeywellsafety.com/Americas/Product_Cata$\log$ /Protective_Clothing.aspx

Draeger: https:/www.draeger.com/Library/Content/protectionif-9046985-en.pdf

Respirex: http://www.respirexinternational.com/en/products/

Kimberly-Clark- http://www.kcprofessional.com/brands/kleenguard

Lakeland- www.lakeland.com/chemmax_search.aspx

Kappler- http://remote.kappler.com/hazmatch/UserForm.asp

Blauer- http://blauer.com/chembio 